\title{
AS PERCEPÇÕES DOS PROFESSORES DE QUÍMICA GERAL SOBRE A SELEÇÃO E A ORGANIZAÇÃO CONCEITUAL EM SUA DISCIPLINA
}

Shirley Martim da Silva, Marcelo Leandro Eichler e José Claudio Del Pino*

Instituto de Química, Universidade Federal do Rio Grande do Sul, Av. Bento Gonçalves 9500, 91501-970 Porto Alegre - RS

Recebido em 28/5/02; aceito em 23/10/02

\begin{abstract}
THE PERCEPTIONS OF COLLEGE TEACHERS ON THE ORGANIZATION AND SELECTION OF CONCEPTS IN GENERAL CHEMISTRY. The teaching of general chemistry involves both the choice and the organization of its concepts. Although College Teachers make their choices, frequently the text books play an important role in this selection. In the present project we intend to show what are Teachers' perceptions of conceptual organization and selection as well as their perceptions of how to teach general chemistry. This demonstration is carried out through the use of metaphors from new information technologies.
\end{abstract}

Keywords: general chemistry teaching; conceptual organization; college teacher's perception.

\section{INTRODUÇÃO}

Um panorama sobre o que está sendo investigado pela comunidade brasileira dos educadores em química aponta a relação existente entre a linguagem e a formação de conceitos químicos ${ }^{1,2}$. Essa relação vem sendo enfocada sob múltiplas perspectivas, como se depreende de uma revisão bibliográfica em alguns periódicos nos quais publica essa comunidade. A partir dessa revisão é possível inferir que:

1. as significações dadas às palavras têm um papel fundamental na compreensão que os sujeitos fazem dos conceitos científicos ${ }^{3-6}$;

2. essas significações e os processos de pensamento, tais como a abstração e a generalização, estão relacionados ${ }^{3,5,7,8}$;

3. em função disso, evidencia-se que os alunos de ensino médio têm dificuldades de compreensão dos fenômenos que constituem a ciência química, por exemplo, não interpretam as diferentes interações das substâncias envolvidas nos processos físicoquímicos ${ }^{9,10}$ ou não reconhecem similaridades entre fenômenos de aspectos perceptivos diferenciados ${ }^{10}$;

4. no âmbito da escola básica, seja através dos livros didáticos ${ }^{3,6,11-15}$, seja pelas falas de professores e de alunos ${ }^{16-19}$, evidencia-se que os termos científicos têm seu conteúdo semântico ou sua estrutura sintática modificados (por supressão, generalização ou reconstrução), podendo, inclusive ser esvaziados; e

5. tais modificações podem provocar confusões conceptuais ${ }^{3,19}$ ou problemas de aprendizagem ${ }^{6}$.

Nesse sentido, parece interessante, ainda, explicitar resumidamente algumas relações de conhecimento e de comunicação presentes no processo de formação de professores. Atualmente, o futuro professor de química da escola básica $\left(\mathrm{P}_{\mathrm{EB}}\right)$ passa por uma formação universitária. Nessa época, ele é um aluno do ensino superior $\left(\mathrm{A}_{\mathrm{ES}}\right)$. Nesse ambiente, durante um tempo variável em torno de quatro anos, os seus professores do ensino superior $\left(\mathrm{P}_{\mathrm{ES}}\right)$ o treinam, instruem ou educam; em outras palavras, eles fazem o aluno conhecer a química e outras disciplinas ou tornam esses saberes possíveis. Concluído o período de sua graduação e iniciado no processo docente, o professor $\left(\mathrm{P}_{\mathrm{EB}}\right)$ é investido de responsabilidades para o treinamento, a instrução ou a educação de seus alunos da escola básica $\left(\mathrm{A}_{\mathrm{EB}}\right)$. Esse

*e-mail: aeq@iq.ufrgs.br processo de formação de professores e alunos, de intercâmbios de saberes e conhecimentos, para efeitos de brevidade, pode ser representado da seguinte maneira:

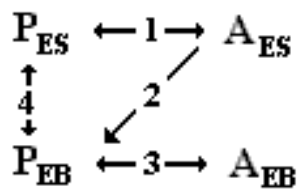

É possível verificar que o estudo da transposição didática ${ }^{17,20}$ tem destacado a terceira e a quarta etapas do processo da formação dos professores. Por exemplo, na comunidade dos educadores químicos brasileiros, a maior parte dos estudos da linguagem utilizada na comunicação do conhecimento químico ${ }^{3-5,7,9,19,21}$ e das críticas aos livros didáticos ${ }^{3,11,14,15,18}$ tem centrado ênfase na terceira etapa, naquela onde ocorreriam trocas entre o professor de química $\left(\mathrm{P}_{\mathrm{EB}}\right)$ e os alunos $\left(\mathrm{A}_{\mathrm{EB}}\right)$ da escola básica. Já a quarta etapa está relacionada ao processo de formação continuada de professores, uma das diretrizes de nosso grupo de pesquisas ${ }^{22,23}$ que tem sido investigada em trabalhos de pós-graduação ${ }^{24,25}$.

No entanto, entende-se que as duas etapas anteriores do processo de formação dos professores podem influir nas relações atinentes à transposição didática. Nessas etapas, de forma semelhante ao que fora apontado para o ensino médio, também ocorreriam transformações equivocadas de conhecimento. Algumas baseadas na insuficiência de compreensão da linguagem da química, outras na manutenção da cultura de estruturação dos conceitos científicos com o exacerbado suporte dos conteúdos curriculares presentes em livros didáticos.

Nesse sentido, ao se especular pelas prováveis causas ou fatores intervenientes ou geradores das dificuldades de alunos e professores com a linguagem da química, vimos desenvolvendo um projeto cujo objetivo geral visa uma descrição, interpretação e análise semântica e sintática da enunciação de conceitos químicos no universo de discurso da formação do futuro profissional em química. A opção por esse foco justifica-se por entendermos que nesse nível é que se aprofunda - e por vezes se cristaliza, cedo demais - a construção do conhecimento químico, socialmente aceito e partilhado por uma certa comunidade. 


\section{A disciplina de química geral e os livros didáticos no nível superior}

No desenvolvimento de nosso projeto, a primeira fase consiste em inventariar os termos mais recorrentes nos principais textos dissertativos de caráter científico utilizados como material didático de química geral nos cursos de graduação em química. Posteriormente, esse inventário é seguido por análises lingüística e conceitual que nos permitem postular sobre os diferentes perfis da enunciação do conhecimento em química ${ }^{26,27}$. Uma vez que não é o objetivo do presente artigo entrar em tal discussão, cabe justificar a escolha por essa disciplina e refletir sobre alguns problemas relacionados a ela.

Normalmente, a disciplina de química geral é a primeira disciplina oferecida por qualquer instituto de química aos seus próprios calouros $^{28}$. Ela aborda um conjunto de assuntos que abrange muitos dos aspectos da química, ainda que superficialmente. Esses mesmos assuntos serão, posteriormente, desenvolvidos ao longo de todo o curso de graduação. Além disso, essa disciplina tem ainda um papel muito importante no sentido de reforçar a motivação dos calouros em continuar se dedicando ao estudo da área que eles escolheram para se profissionalizar.

No contexto acadêmico de outras carreiras, é possível notar que os estudantes universitários, muitas vezes, vêem a química geral como um obstáculo insuperável ${ }^{29}$. Nesse sentido, a maioria dos estudantes de química geral entra em classe simplesmente para satisfazer as exigências de sua graduação.

Porém, os estudos sobre a evasão ${ }^{30,31} \mathrm{e}$ as reprovações ${ }^{30}$ nos cursos de química mostram que os obstáculos aparecem, inclusive, de fronte dos estudantes da graduação em química. Em um estudo realizado no âmbito da Universidade de Brasília ${ }^{30}$ foi possível concluir que parecem existir causas variadas para a evasão e para as reprovações que se manifestam em distintos momentos do curso. A partir das análises realizadas, pode-se apontar o ponto de origem da evasão: as disciplinas obrigatórias, previstas no início do fluxo do currículo. Um outro estudo $^{31}$ incluiu diversas universidades públicas brasileiras e indicou que a evasão do curso de química estaria ligada às reprovações em disciplinas situadas nos dois primeiros anos do curso.

Portanto, esses trabalhos mostram a relação entre a evasão e o desempenho acadêmico do aluno durante o curso. Entre as medidas sugeridas para a solução de tal problema, incluiu-se: a revisão curricular, a mudança na metodologia do ensino e a implementação de um sistema eficaz de orientação acadêmica ao aluno ${ }^{31}$.

Em direção a essas conclusões, é possível trazer alguns questionamentos aos conteúdos da disciplina de química geral. Por exemplo, é muito raro encontrar nos livros didáticos dessa disciplina uma relação explícita e direta de aspectos da vida, tais como a relação com a produção industrial, o consumo humano ou a saúde ${ }^{32}$.

Entretanto, talvez o pior seja a ênfase dos livros didáticos na resolução de problemas algorítmicos mais do que no entendimento conceitual $^{29}$. Isso introduziria obstáculos adicionais para a aprendizagem da maioria dos estudantes.

No ensino da disciplina de química geral destacam-se também objetivos mais amplos ${ }^{33}$. Indica-se a importância de uma introdução aos fundamentos teóricos da ciência química, ressaltando os aspectos históricos e epistemológicos. Aponta-se, também, a análise da importância da química no desenvolvimento social, industrial e de outras ciências, bem como a problemática do descontrole de suas aplicações.

Esses diagnósticos parecem, inclusive, aumentar o problema da seletividade. Por exemplo, uma pesquisa dos programas vigentes para a disciplina de química geral em faculdades de bioquímica na Argentina $^{34}$ demonstrou não existir consenso sobre o critério a ser utilizado para a seleção dos temas. Além do mais, haveria uma disparidade entre a bibliografia citada e, em alguns casos, uma falta de atualização.

É possível notar que o sistema educacional é forçado a aplicar, razoavelmente, princípios de seleção ${ }^{34}$. Tais princípios são necessários, por exemplo, para organizar cursos de química, para escrever materiais didáticos introdutórios ou avançados de química. Essa seletividade está relacionada, também, aos recursos limitados de tempo em sala de aula. É necessário entender, entretanto, que qualquer seleção razoável pressupõe valores para decidir o que é mais importante e o que é menos e a que momento.

Como se pode depreender da seção anterior desta introdução, os livros didáticos chegam a pautar o ensino fundamental das diferentes disciplinas. No entanto, compreende-se que essa realidade também é encontrada no ensino superior, particularmente no de quími$\mathrm{ca}^{34}$. Nessa ciência, a necessidade e o surgimento de livros textos ("textbooks") com um gênero próprio de material didático teria surgido a partir do imenso crescimento da extensão dos manuais técnicos ("handbooks") que eram utilizados há 150 anos atrás. Naquela ocasião, os manuais técnicos eram constituídos pela compilação dos artigos mais relevantes publicados em periódicos. Por sua vez, o livro texto era composto por re-compilação, a partir dos manuais. Assim, obtinha-se uma coleção estruturada de recortes de experiências, eventos e teorias. Porém, mesmo nos últimos 20 anos, quando foram providenciados novos e excelentes negócios para fomentar a escritura de livros textos universitários, ainda existe uma tendência dominante em química de se escrever livros textos como uma recompilação dos experimentos e das teorias efetivamente realizadas e debatidas.

Então, dada à impossibilidade de uma supervisão sobre a produção do conhecimento químico atual, tais livros textos não devem ser entendidos como uma condensação de fontes primárias, ou seja, relatos de pesquisas ou análises e sínteses teóricas. Os livros textos podem, então, ser entendidos como uma seleção arbitrária de informação. Em sentido estrito, a seleção é arbitrária porque ninguém pode dar quaisquer razões objetivas para justificá-la ${ }^{34}$.

Alguns autores de livros textos de química geral ${ }^{35-37}$ têm apontado suas justificativas e sugerido quais seriam as idéias centrais ou principais relacionadas à química. O propósito desses autores é subsidiar as escolhas de currículo para o primeiro ano do ensino superior (disciplina de química geral). Os conceitos que são considerados centrais e recomendados como conteúdos curriculares são: atomismo (unidades constitutivas da matéria: átomos, moléculas e íons), ligação química (como essas unidades estão ligadas em materiais macroscópicos, como cristais e metais), geometria molecular (a interpretação geométrica do arranjo tridimensional dessas ligações), reações químicas (formação e transformação dos materiais), teoria cinética (descrição dos movimentos das unidades constituintes, incluindo os relacionados a sua formação), termodinâmica (a energia é parte constituinte necessária das descrições e das explicações das transformações químicas).

Quanto ao objetivo a ser alcançado nesse nível de ensino, ressalta-se que o principal é a educação em química achar um modo de construir uma ponte entre o percebido e o imaginado ${ }^{35}$. Portanto, entende-se que a química, ou melhor, o primeiro ano do ensino superior, deveria subsidiar ao estudante entendimento suficiente da estrutura química e das propriedades químicas para capacitá-lo a entender a constituição material presente nas coisas vivas e nas inanimadas ${ }^{37}$.

No curso dessa revisão bibliográfica, foi possível depreender os principais conceitos a serem abordados na disciplina de química geral, algumas justificativas para essa escolha, as principais dificuldades relacionadas ao ensino e à aprendizagem dessa disciplina e a influência do livro didático na estruturação curricular. Uma vez que 
pretendemos captar as percepções dos professores de química geral de nossa universidade em relação a esses temas, resta citar a maneira como foi conduzida nossa investigação.

\section{METODOLOGIA}

Os livros didáticos possuem uma macroestrutura, que pode ser considerada a espinha dorsal sobre a qual os conteúdos dos livros são apresentados. Essa macroestrutura reflete o planejamento feito pelos autores. Um livro, em geral, começa pelos assuntos que são considerados mais fundamentais ou mais necessários para a progressão conceitual. A seguir, são ordenados os conteúdos conforme o grau de dependência dos próximos nos anteriores. Essa estrutura é chamada de linear. O livro parece ter uma progressão, convergindo para os conteúdos finais, os mais dependentes dos conceitos anteriores. Essa estrutura, bem como a progressão dos conteúdos que subjaz a ela, é um fruto de uma tecnologia de produção e de disseminação do conhecimento que tem o papel como suporte ${ }^{38}$.

As novas tecnologias da informação têm possibilitado outras macroestruturas, como por exemplo a hipermídia ${ }^{39}$, que utiliza como suporte os meios digitais. A hipermídia consiste em um conjunto de tópicos de informação interligados ativamente de diversas formas, possibilitando consultas imediatas em ordem ditada pelo leitor. Esse tipo de estrutura tem recentemente se popularizado muito, principalmente, devido à Internet e às ferramentas de hipertexto incorporadas em "software" educativos.

O projeto de estruturas linear ou hipermídia, visando a confecção de materiais didáticos, por exemplo, permite evidenciar a seleção e a organização de conteúdos de uma área do saber. Utilizamos esse projeto como metáfora e convidamos os professores de química geral do Instituto de Química da UFRGS a participarem de nossa investigação. Para eles foi enviada uma carta-convite, na qual se solicitava a elaboração de um diagrama de tópicos visando a uma estrutura hipermídia. Esse diagrama seria resultado da reflexão sobre três perguntas que foram indagadas na carta-convite: 1) quais são os principais conhecimentos necessários a um bom entendimento de Química Geral?; 2) como podem esses conhecimentos ser classificados?; 3) de que forma (maneira, modo, jeito) esses conhecimentos se inter-relacionam? Essa carta-convite, então, continha um exemplo de diagrama, que pode ser visto na Figura 1.

As cartas-convite foram remetidas para onze professores. Dentre esses, sete responderam, produzindo uma representação para a interligação conceitual, por tópicos, subjacente à estrutura hipermídia.

As representações produzidas pelos professores foram decompostas e analisadas a partir dos tópicos selecionados e de suas

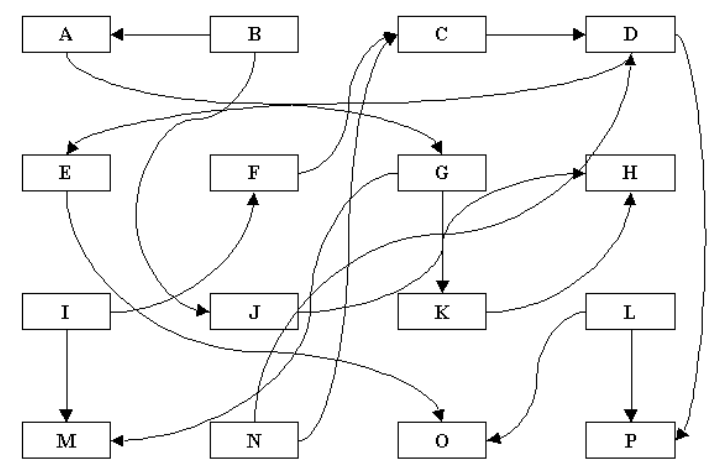

Figura 1. Esboço de uma estrutura hipermídia poliierárquica, onde os tópicos se encontram remissiva e ativamente interligados interligações. Os tópicos foram retirados da representação e listados, por ordem alfabética, em duas colunas iguais, uma ao lado da outra. Uma das colunas incluiria os conceitos chamados "de saída" (S), a outra os "de entrada" (E). Os conceitos de saída podem, assim, ser considerados necessários para os de entrada. Com isso, quis se buscar um entendimento sobre a migração entre os tópicos, procurando por suas dependências. Através desse procedimento, também, é possível quantificar as interligações. Os tópicos de saída mais incidentes podem, então, ser considerados os mais fundamentais. De outro lado, os tópicos de entrada que incluem o maior número de ligações podem ser considerados os de maior convergência conceitual, ou seja, os tópicos anteriores pareceriam migrar para esses. Os tópicos de saída seriam os fundamentos para os tópicos de entrada, que seriam o objetivo a ser alcançado.

Uma análise como essa permite ordenar, em grau de importância, os tópicos, ou os conceitos de química que eles indicam. Essa ordem é importante para o desenvolvimento de outras pesquisas que vimos desenvolvendo, que objetivam a análise da enunciação de conceitos químicos ${ }^{26,27}$ nos principais livros didáticos de química geral utilizados nos cursos de graduação em química ${ }^{40}$.

A análise das representações produzidas pelos professores foi seguida de uma entrevista semi-estruturada, que objetivou clarear nosso entendimento sobre as percepções dos professores em relação à seleção e à ordenação conceitual, à influência da linguagem na química, aos aspectos pedagógicos, etc. As perguntas-chave nessa entrevista foram:

1. Que tipo de conhecimento é necessário para a adequada compreensão da linguagem química, apresentada nos materiais didáticos de Química Geral no ensino superior?

2. Na sua opinião, as relações estabelecidas entre a química, a matemática e a física são suficientes para a adequada compreensão e expressão do conhecimento em questão?

3. Sob quais condições foi feita a seleção dos conceitos representados graficamente?

4. Como você elaborou essa representação conceitual? Descreva o seu processo criativo.

5. Há algum conceito que se pode considerar a síntese do conhecimento em química geral? Por quê?

6. A estrutura apresentada segue alguma hierarquia conceitual?

7. Quais foram os critérios utilizados para estabelecer as relações entre os conceitos?

8. A maneira como se estrutura o desenvolvimento de um determinado assunto, muitas vezes deixa subtendido ou omite-se algo. Numa análise posterior dessa representação, haveria a inserção ou exclusão de algum conceito?

As entrevistas foram, posteriormente, transcritas. Os professores entrevistados tiveram seus nomes substituídos, mantendo a indicação de gênero. Na próxima seção, as falas dos professores são utilizadas como suporte para uma reflexão sobre a disciplina de química geral, seu conteúdo e suas estratégias.

\section{RESULTADOS E DISCUSSÃO}

Os professores produziram representações da seleção e da organização do conhecimento químico bastante diferenciadas. Algumas dessas representações foram tão simplificadas que delas não foi possível extrair nada de revelador. Por exemplo, a Profa. Sabrina apenas esquematizou em um fluxograma a interação da química geral com outras idéias amplas, como: "física, conceitos básicos de química, vocabulário português e matemática". Não houve indicação de nenhum conceito específico dessas amplas áreas do conhecimento.

Portanto, das sete representações entregues pelos professores cinco foram passíveis da análise que descrevemos na seção anterior. 
Na segunda etapa dessa nossa investigação, na qual entrevistamos os professores, não foram consultados os professores que elaboraram essas representações muito simples. Além do mais, durante a etapa das entrevistas, uma das professoras se encontrava fora do país, em período de pós-doutoramento. Foram entrevistados, assim, quatro dos onze professores inicialmente convidados para participar de nossa investigação.

Uma representação foi esquematizada tal qual um hipertexto, conforme pode ser visto na Figura 2. Ela apresentava uma hierarquia conceitual, na qual grandes campos conceituais foram apresentados em uma ordem numérica. Esses campos são ainda descritos pela citação de seus constituintes. Uma leitura desse esquema permite inferir que a maior concentração de inter-relações é encontrada nos temas termodinâmica e ligação química.

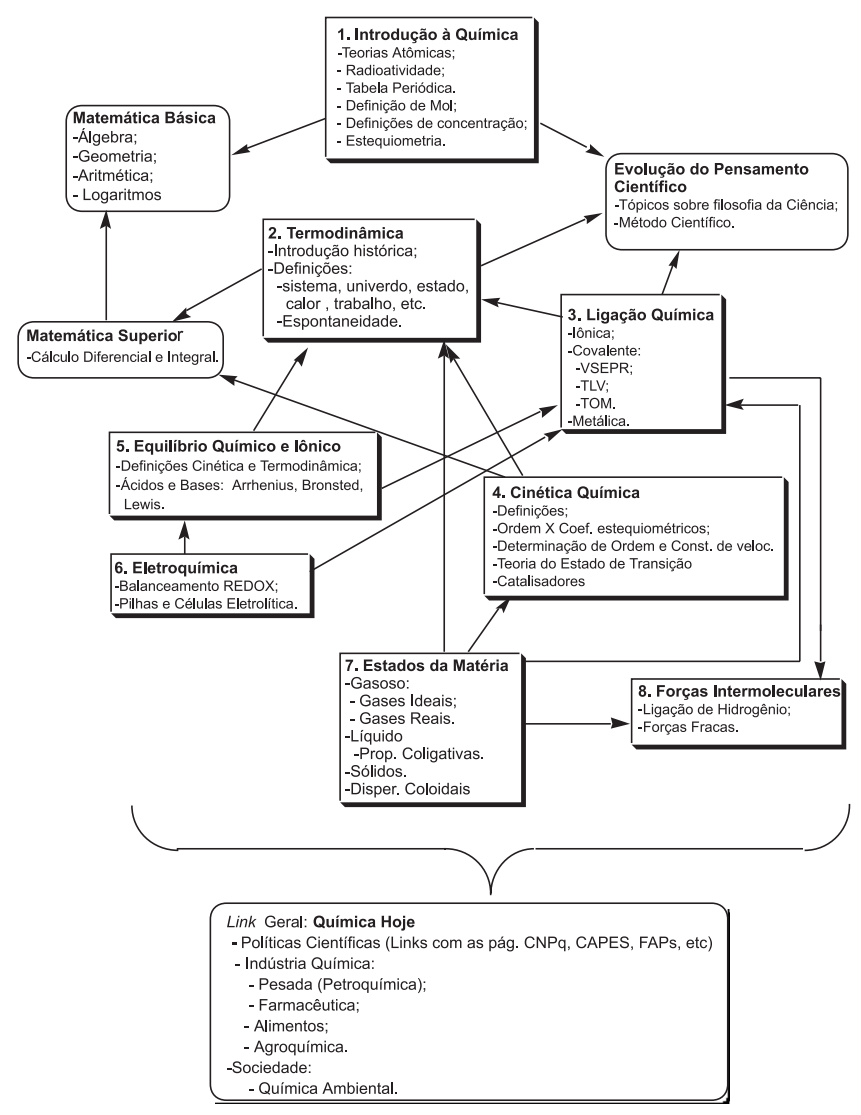

Figura 2. Representação proposta pelo Prof. Pedro

Em uma das representações, o nível de integração conceitual é consideravelmente ampliado, são apontados 86 conceitos das áreas da química, da física e da matemática. A integração, feita por diversos modos, apresenta 145 ligações. Em função das dimensões dessa representação não é possível apresentá-la neste artigo. No centro dela está posto a química geral. Na borda superior encontra-se a Química e suas quatro grandes divisões: analítica, orgânica, inorgânica e físico-química. Na borda direita, a física e na esquerda, a matemática. Os conceitos foram então dispostos entre o centro e as bordas, conforme descreve a professora: "[Profa. Renata]: depois eu comecei a ver pela minha seqüência lá na disciplina. Eu viria para soluções (apontando para sua representação) (...). Depois cinética. Em cinética eu preciso mais de matemática, então vou colocar cinética do lado de cá (lado esquerdo), porque eu coloquei a matemática aqui, a termodinâmica precisa daqui (lado esquerdo), mas precisa de lá (lado direito), mas bom, vou deixar ela aqui.... eu fui mais ou menos meio que me esparramando por aqui (indicando o centro da representação)". Nesse esquema, é mais difícil notar quais são os conceitos que apresentam maior interligação conceitual ou que poderiam ser considerados mais centralizadores.

No entanto, a maioria das representações não seguiu a sofisticação que foi apresentada pelos professores Pedro e Renata. Pode-se, por vezes, constatar as dificuldades enfrentadas pelos professores para construir uma proposição onde fosse possível perceber uma integração conceitual consistente. Entre as razões expressas pelos professores, destaca-se como exemplo: "[Profa. Dilma]: eu fiz de uma forma bem simples o trabalho que tu pediste (falando com o entrevistador), pegando só as unidades da química geral, sem abrir essas unidades. Então eu peguei essas unidades e o que elas precisam como pré-requisitos do $2^{\circ}$ grau e para onde é que elas iam, para que servia o conteúdo da química geral para as disciplinas posteriores do curso de química, então foi essa a minha idéia”. Essa representação pode ser vista na Figura 3.

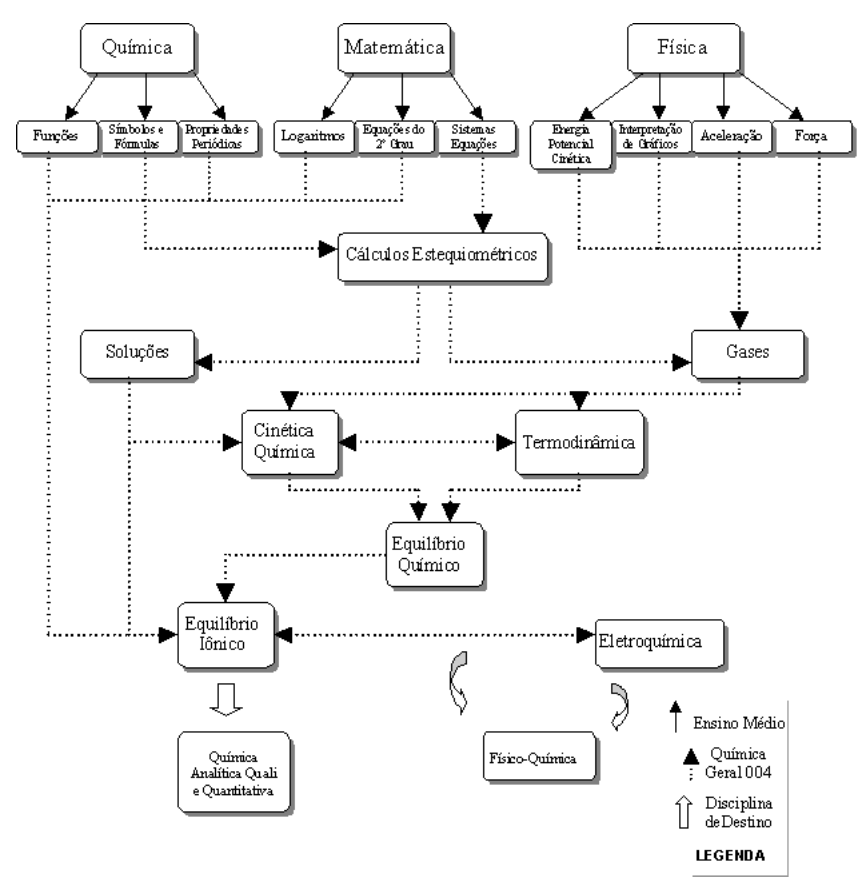

Figura 3. Adaptação da representação elaborada pela Profa. Dilma

Mas houve casos em que a seleção e a inter-relação tornaram-se difíceis, entre outros motivos, pela pouca diferenciação, como manifesta um dos professores: "[Prof. Inácio]: Acho que está tudo tão entrelaçado, não consigo ver o que seja mais importante, acho que o importante é ter uma boa noção do conteúdo todo, não me atreveria a centralizar em algum ponto".

Dessa forma, para extrair das representações apresentadas pelos professores os conceitos centrais foi necessário analisá-las conforme descrito na seção anterior. A partir de tal análise foi possível identificar e quantificar a integração dos cinco conceitos mais indicados pelos professores, conforme a Tabela 1 .

O somatório das indicações de todos os professores nos permite listar em ordem decrescente os conceitos de maior recorrência, quais sejam: equilíbrio químico, ligação química, estequiometria, termodinâmica química e equilíbrio iônico. A indicação de cada um dos professores para esses termos pode ser visto na Tabela 2. Con- 
Tabela 1. Os cinco conceitos de maior incidência na representação de cada um dos professores

\begin{tabular}{lll}
\hline & Profa. Dilma & \\
\hline Conceitos & $\mathrm{S}$ & $\mathrm{E}$ \\
\hline Cinética Química & 2 & 3 \\
Equilíbrio Iônico & 1 & 4 \\
Termodinâmica & 3 & 2 \\
Equilíbrio Químico & 2 & 2 \\
Cálculo Estequiométrico & 2 & 1 \\
Eletroquímica & 0 & 3 \\
Gases & 2 & 1 \\
Soluções & 2 & 1 \\
\hline & Profa. Heloísa & \\
\hline Conceitos & $\mathrm{S}$ & $\mathrm{E}$ \\
\hline Equilíbrio Químico & 2 & 8 \\
Estequiometria & 7 & 2 \\
Eletroquímica & 0 & 8 \\
Soluções & 5 & 3 \\
Equilíbrio Iônico & 1 & 6 \\
Cinética Química & 2 & 4 \\
Termodinâmica & 2 & 4 \\
\hline
\end{tabular}

\begin{tabular}{|c|c|c|}
\hline \multicolumn{3}{|c|}{ Prof. Inácio } \\
\hline Conceitos & $\mathrm{S}$ & $\mathrm{E}$ \\
\hline Estrutura Atômica & 5 & 0 \\
\hline Ligação Química & 0 & 5 \\
\hline Ácidos e Bases & 1 & 2 \\
\hline Forças Intermoleculares & 2 & 1 \\
\hline Propriedades dos Sólidos & 1 & 1 \\
\hline Iônicos e Metálicos & & \\
\hline Tabela periódica & 1 & 1 \\
\hline \multicolumn{3}{|c|}{ Prof. Pedro } \\
\hline Conceitos & $\mathrm{S}$ & $\mathrm{E}$ \\
\hline Ligação Química & 3 & 3 \\
\hline Termodinâmica & 2 & 4 \\
\hline Estados da matéria & 4 & 0 \\
\hline Cinética Química & 2 & 1 \\
\hline Equilíbrio Químico e Iônico & 2 & 1 \\
\hline \multicolumn{3}{|c|}{ Evolução do Pensamento Científico } \\
\hline \multicolumn{3}{|c|}{ Profa. Renata } \\
\hline Conceitos & $\mathrm{S}$ & $\mathrm{E}$ \\
\hline Ligação Química & 9 & 3 \\
\hline Equilíbrio Químico & 5 & 4 \\
\hline Estequiometria & 0 & 7 \\
\hline
\end{tabular}

forme referenciamos antes, tais indicações nos permitiram selecionar os capítulos dos livros didáticos de química geral nos quais empreendemos as análises lingüísticas e conceituais relacionadas ao nosso projeto em curso.

A decisão sobre os requisitos e as convergências temáticas de um certo tópico sugere as percepções dos professores sobre o encadeamento a ser dado aos conteúdos de sua disciplina. Dessa forma, além da seleção dos conceitos centrais, essa análise nos permitiu inferir alguns possíveis caminhos para o encadeamento conceitual. Assim, coletamos a totalidade das indicações feitas por todos os professores para um mesmo conceito e as relacionamos. Por exemplo, na Figura 4 é possível verificar os tópicos que os professores associaram ao equilíbrio químico. Como se pode ver, temas como ácidos e bases fracos, espontaneidade de reações químicas e sais pouco solúveis foram considerados tanto como necessidades anteriores quanto possibilidades posteriores. Outros temas semelhantes foram citados com nomes diferentes, como, por exemplo, espontaneidade de reações químicas e termodinâmica, onde essa incluiria aquela.

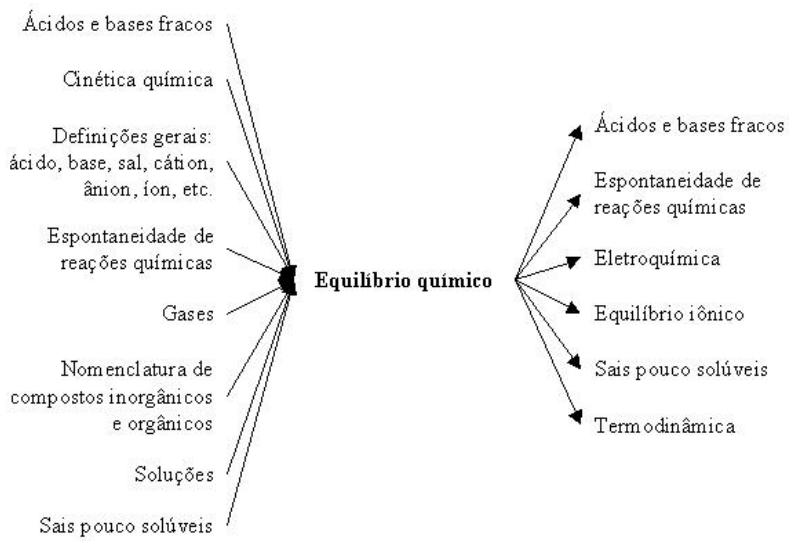

Figura 4. Encadeamento conceitual para equilíbrio Químico. A esquerda estão os conceitos de saída e, à direita, os de entrada

Alguns professores indicaram os conceitos que seriam mais recorrentes na comunicação do conhecimento em química geral. Alguns fizeram indicações pontuais, mas houve quem preferiu apontar idéias mais gerais. Entre os primeiros, cita-se a estequiometria: "[Profa. Renata] Tudo isso acaba me levando ao cálculo estequiométrico e Estequiometria (...) O que tu mais usas para o resto da química geral, na verdade, é estequiometria. Tu vês lá no início e depois tu passas o resto do curso buscando estequiometria. Tu estás fazendo um exercício de equilíbrio químico, tu tens que ir lá ver a relação estequiométrica...”. O equilíbrio químico: "[Profa. Renata] (...) se vê muito equilíbrio, é uma base. Toda a quantitativa e qualitativa que vem depois se apóia em equilíbrio". E a termodinâmica: "[Prof. Pedro] Termodinâmica é fundamental. Tudo está centrado basicamente na

Tabela 2. Presença nas representações dos professores dos conceitos mais indicados

\begin{tabular}{lccccccccccc}
\hline & \multicolumn{3}{c}{ Profa. Dilma } & \multicolumn{2}{c}{ Profa. Heló́sa } & \multicolumn{2}{c}{ Prof. Inácio } & \multicolumn{2}{c}{ Prof. Pedro } & \multicolumn{2}{c}{ Profa. Renata } \\
Conceitos & S & E & S & E & S & E & S & E & S & E \\
\hline Equilíbrio Químico & 2 & 2 & $*$ & $*$ & 2 & 7 & 2 & 1 & 5 & 4 & 25 \\
Ligação Química & $*$ & $*$ & $*$ & 5 & $*$ & $*$ & 3 & 4 & 9 & 3 & 24 \\
Estequiometria & 2 & 1 & $*$ & $*$ & 7 & 2 & 2 & $*$ & 7 & 7 & 21 \\
Termodinâmica Química & 3 & 2 & $*$ & $*$ & 2 & 3 & 1 & 5 & 2 & 2 & 21 \\
Equilíbrio Iônico & 1 & 4 & $*$ & $*$ & 1 & 5 & 2 & 1 & 1 & 1 \\
\hline
\end{tabular}


termodinâmica. Para explicar toda a reatividade a gente precisa explicar o conceito de estabilidade, espontaneidade, (...) Então tudo isso remete aos fundamentos da termodinâmica".

No entanto, a indicação pontual não pareceu tão adequada para uma das professoras, que preferiu apontar algumas idéias fundamentais mais amplas: "[Profa. Dilma] (...) eu tinha colocado duas coisas. A primeira é que a composição da matéria segue uma determinada proporção (...). Então para isso o aluno tem que ter um pouco de conhecimento de atomismo e de estequiometria. Ele não precisa entender a ligação química em si, mas ele precisa entender, aceitar, abstrair a existência do átomo e do grupamento atômico (...). A segunda, o conceito de energia, pois toda a transformação da matéria vai ser construída, vai acontecer em cima de um fluxo de energia. Então uma transformação espontânea é aquela em que aquele sistema atinge um nível de energia mais baixo liberando essa energia, produzindo trabalho, produzindo calor (...). Eu acho que esses dois, são dois grandes conteúdos: proporção e o fluxo de Energia, para entender a transformação da matéria. E tudo isso é o que a gente procura nos conteúdos de química geral passar para os alunos".

Uma vez que a disciplina de química geral está no início do curso, ela se constitui uma disciplina de interface entre o conhecimento previamente estruturado, nível do ensino básico, e aqueles que constituirão a formação do profissional na área de química. Nesse momento, a seleção e a integração conceitual são mais difíceis, devido ao grau de abstração dos conceitos da química. A compreensão das peculiaridades desse momento parece, portanto, ser algo essencial, conforme aponta um dos professores: "[Prof. Pedro] a química geral é um momento importantíssimo, onde o aluno toma o contato com o curso de química. É um grande contato com o curso de química e ali, claro, isso aqui é um mar de coisas. Isso aqui é toda a química, mas alguma maneira tem que se encontrar para tocar nesses pontos (os conceitos postos na representação) e salientar a importância e a maneira de se tornar menos pesado e tentar correlacionar com as coisas da natureza mesmo. O que a gente pode explicar, os processos industriais para mostrar a abrangência e mostrar a beleza, a beleza que a gente consegue ver imediatamente. Porque, claro, esperar um grande grau de abstração e se dar conta de tudo que é importante quando os caras estão entrando, com 19, 18 anos, é pedir demais. Até hoje, para muitas pessoas com 40 anos, é difícil tu te dares conta do que é importante mesmo...".

As dificuldades de aprendizagem dos alunos são fatores intervenientes na construção do conhecimento. Os professores foram questionados em relação às concepções que os alunos traziam nível médio, queria se saber como eles percebiam essas concepções, se elas ajudariam ou atrapalhariam no desenvolvimento do conteúdo curricular trabalhado em sala de aula. Os exemplos trazidos pelos professores vão desde a falta de articulação de conceitos até os equívocos de compreensão.

A articulação conceitual foi, por exemplo, destacada em noções relacionadas à energia: "[Prof. Inácio] Alguns tem idéia de entropiadesordem. Poucos! Agora entalpia- calor, não! Para eles $\Delta H$ é entalpia e pronto! Não me lembro de ninguém ter relacionado com calor e muito menos com calor sob condições restritivas". Os equívocos de compreensão e as dificuldades decorrentes para o ensino têm exemplo na cinética: "[Profa. Renata] Cinética é um exemplo típico. Eles acham na expressão da ordem da reação, a lei de velocidade. Eles pegam os coeficientes estequiométricos e põem lá. Então, eles não têm no $2^{\circ}$ grau essa noção de mecanismo, que é uma reação, que tu tens ali dois fulanos, mais três fulanos, aquilo não pode ocorrer numa única etapa, pois uma única etapa tu terias colisão de cinco moléculas ao mesmo tempo. Basta ver dois mais três reagindo, possivelmente aquele mecanismo, aquela reação ocorre num mecanismo de mais de uma etapa. E a etapa lenta é que vai mandar na lei da velocidade, portanto a lei da velocidade só tem condições de ser estabelecida a partir de resultados experimentais .... Então, em cinética, às vezes atrapalha". E, também, na estequiometria: "[Profa. Renata] (...) eles chegam aqui com dificuldade incrivel de entender o que é mol. Eu não entendo isso! Eles não sabem direito o que é mol! E eles não sabem, eles fazem uma confusão. Por que uma molécula de água é 18 u.m.a e 1 mol de molécula de água é $18 \mathrm{~g}$ ?".

Porém, os erros conceituais, alicerçados nas distorções apreendidas durante o ensino médio, mais citados pelos professores estiveram ligados à estrutura atômica, principalmente à compreensão do modelo orbital. Um exemplo dessa constatação: "[Profa. Dilma] $o$ maior exemplo de erro é o conceito de números quânticos. $O$ aluno vinha do colégio com o conjunto dos números quânticos de um determinado elétron sendo o endereço do elétron, onde ele está localizado dentro da estrutura atômica que é um conceito absolutamente errado, e os alunos sabiam exatamente assim...". Nesse sentido, alguns professores procuram indicar os equívocos de compreensão do estudante e apontar as necessárias soluções: "[Prof. Pedro]: (...) eles têm que ver o fundamento, não pode ser banalizado, não pode ser transformado em bolinhas. Não tem bolinha nenhuma. A primeira coisa que eu falo nas aulas de ligação química, na teoria atômica, aliás, é acabar com aquela idéia do elétron dando voltinha. Elétron não dá voltinhas. Elétron não é bolinha! Ele tem um comportamento dualístico, ele é onda-partícula, simultaneamente". Essas falas vêm corroborar os resultados de trabalhos investigativos que indicam a existência de concepções prévias dos alunos e que mostram as suas resistências, tornando difíceis as mudanças de referencial conceitual $^{41,42}$.

No entanto, esses exemplos trazidos pelos professores podem ser antigos, pois a disciplina química geral sofreu alterações em suas ementas, conforme é possível verificar na Tabela 3. Atualmente, modelos atômicos e ligação química não são mais conteúdos apresentados no primeiro semestre aos alunos. Talvez as dificuldades manifestadas pelos alunos possam ter influenciado as modificações da disciplina.

Obviamente, o choque entre o ensino superior e o ensino médio não se dá apenas em relação aos conhecimentos. Na universidade, há uma outra realidade, bastante diferente daquela a qual o aluno do ensino médio estava acostumado. Os professores destacam o ritmo acelerado e as exigências de autonomia nos estudos, por exemplo: "[Profa. Renata] (...) eu sinto lá na Geral que a gente trabalha muito depressa, muito conteúdo. Então é muito diferente do $2^{\circ}$ grau, onde eles vêem um conceito e ficam horas naquele conceito e fazem exercícios e treinam exercícios e (...). Aqui, além de tu veres de novo alguma coisa num enfoque um pouco diferente, tu vês eles arregalarem os olhos. (...). O conceito eles já conhecem, mas tu aprofundas. Tu passas muito rápido, porque tu tens conteúdo a vencer. Então eu acho que isto é um problema (...), eles são muito imaturos no inicio. (...) eles não vem preparados para estudar por conta própria. Eles querem receber tudo. Então eu acho que tem esse problema de ordenamento com que as coisas são jogadas e tem o problema da velocidade com que o conteúdo é colocado em cima deles".

A passagem entre os níveis de ensino, também, suscita a modificação de posturas filosóficas e a abertura a outros tipos de questionamentos que, conforme a percepção dos professores, não seriam hábitos dos alunos. As indicações feitas pelos professores se relacionam à história das ciências: "[Prof. Pedro] (...) para mim a filosofia é importante para compreender o fundamento da química, talvez das ciências. (...) Tu vais precisar, também, estar remetendo sempre para a evolução do pensamento científico". Ou ao contexto da curiosidade e da vontade de saber do aluno: "[Profa. Dilma]: Ele tem que estar aberto a certos questionamentos, por que eles muitas vezes perguntam: 'Por que a gente estuda química geral?' Então, 
Tabela 3. Transformações ocorridas na disciplina de Química geral

\begin{tabular}{|c|c|c|c|c|c|}
\hline $\begin{array}{l}\text { Vigência do } \\
\text { Currículo }\end{array}$ & $\begin{array}{l}\text { Código da } \\
\text { Disciplina }\end{array}$ & $\begin{array}{l}\text { Denominação } \\
\text { da Disciplina }\end{array}$ & Súmula & Carga horária & Matrícula \\
\hline \multirow[t]{5}{*}{ 1984-1994 } & Qui 101 & Química Geral I & $\begin{array}{l}\text { Classificação dos elementos e Estrutura Atômica. } \\
\text { Estrutura extranuclear. Ligação Química. } \\
\text { Compostos Complexos. Estados de Agregação. }\end{array}$ & $4 \mathrm{~h} / \mathrm{a}$ & $1^{\mathrm{a}}$ \\
\hline & Qui 102 & Química Geral II & $\begin{array}{l}\text { Noções de Termodinâmica Química. Equilíbrio } \\
\text { Químico. Equilíbrios Iônicos. Teoria das Reações } \\
\text { de Oxidação-Redução. Eletrólise. Cinética Química. } \\
\text { Colóides. }\end{array}$ & $4 \mathrm{~h} / \mathrm{a}$ & $2^{\mathrm{a}}$ \\
\hline & Qui 107 & $\begin{array}{l}\text { Química Geral } \\
\text { Experimental I }\end{array}$ & $\begin{array}{l}\text { Aparelhos e materiais de uso comum. Trabalhos em } \\
\text { vidro. Montagem de aparelhos. Balança Analítica. } \\
\text { Trabalhos experimentais relacionados com o } \\
\text { conteúdo de disciplina de QuímicaGeral. }\end{array}$ & $4 \mathrm{~h} / \mathrm{a}$ & $2^{\mathrm{a}}$ \\
\hline & Qui 123 & Química Inorgânica I & $\begin{array}{l}\text { Estudos dos elementos químicos das séries "s", "p", } \\
\text { "d" e "f": suas propriedades, reações e usos. }\end{array}$ & $4 \mathrm{~h} / \mathrm{a}$ & $5^{\mathrm{a}}$ \\
\hline & Qui 124 & Química Inorgânica II & $\begin{array}{l}\text { Estudo das estruturas de compostos inorgânicos, } \\
\text { mecanismos de reações inorgânicas e Química dos } \\
\text { compostos de coordenação. }\end{array}$ & $4 \mathrm{~h} / \mathrm{a}$ & $6^{\mathrm{a}}$ \\
\hline \multirow[t]{3}{*}{ 1995-1998 } & Qui 142 & Química Geral & $\begin{array}{l}\text { Estequiometria. Soluções. Estado Gasoso. Estado } \\
\text { Coloidal. Equilíbrio Químico. Equilíbrio Iônico. } \\
\text { Introdução à Termodinâmica. Cinética Química. } \\
\text { Eletroquímica e Radioquímica. }\end{array}$ & $8 \mathrm{~h} / \mathrm{a}$ & $1^{\mathrm{a}}$ \\
\hline & Qui 143 & Química Inorgânica I-A & Ligação Química. Estudo do Estado Gasoso. & $4 \mathrm{~h} / \mathrm{a}$ & $2^{\mathrm{a}}$ \\
\hline & Qui 145 & Química Inorgânica II-A & $\begin{array}{l}\text { Estudo teórico e prático dos elementos químicos: } \\
\text { ocorrência, obtenção, propriedades, usos e } \\
\text { principais compostos. }\end{array}$ & $5 \mathrm{~h} / \mathrm{a}$ & $3^{\mathrm{a}}$ \\
\hline \multirow[t]{4}{*}{ 1999- } & Qui 003 & $\begin{array}{l}\text { Química Geral } \\
\text { Experimental }\end{array}$ & $\begin{array}{l}\text { Pesagem. Limpeza de vidraria. Chama. Preparo } \\
\text { de soluções. Estado Gasoso. Estequiometria. } \\
\text { Termodinâmica Química. Cinética Química. } \\
\text { Equilíbrio Químico. Equilíbrio Iônico. }\end{array}$ & $4 \mathrm{~h} / \mathrm{a}$ & $1^{\mathrm{a}}$ \\
\hline & Qui 004 & $\begin{array}{l}\text { Química Geral } \\
\text { Teórica }\end{array}$ & $\begin{array}{l}\text { Estequiometria. Soluções. Estado Gasoso. } \\
\text { Introdução à Termodinâmica Equilíbrio Químico. } \\
\text { Equilíbrio Iônico. Cinética Química. Eletroquímica. }\end{array}$ & $4 \mathrm{~h} / \mathrm{a}$ & $1^{\mathrm{a}}$ \\
\hline & Qui 143 & Química Inorgânica I-A & Ligação Química. Estudo do Estado Gasoso. & $4 \mathrm{~h} / \mathrm{a}$ & $2^{\mathrm{a}}$ \\
\hline & Qui 145 & Química Inorgânica II-A & $\begin{array}{l}\text { Estudo teórico e prático dos elementos químicos: } \\
\text { ocorrência, obtenção, propriedades, usos e } \\
\text { principais compostos. }\end{array}$ & $5 \mathrm{~h} / \mathrm{a}$ & $3^{\mathrm{a}}$ \\
\hline
\end{tabular}

não é só uma base! Tem que estar aberto a questionamentos. A gente faz questionamentos, por exemplo, sobre a origem do Universo. Que se estuda o macro e o microcosmo. Então, é na Química que se vê esse microcosmo. Então, ele tem que estar aberto a abstrações, como a existência de átomos, que é um sistema que não se vê, não se enxerga. (...). Ele tem que ter uma percepção lógica. Não é por que a gente não vê alguma coisa que a gente não acredita nela".

Outra dificuldade está relacionada à terminologia científicotecnológica. É inegável a necessidade dos alunos compreenderem as significações dos termos presentes em uma linguagem especializada, como as das ciências em geral $^{43}$ e da química, em particular. A compreensão dos termos permite tanto uma leitura cientificamente mais qualificada do mundo que nos rodeia, quanto um aprofundamento conceitual numa área específica do conhecimento. Existe uma relação entre a terminologia, o ensino e a leitura, conforme manifesta um dos professores: "[Prof. Inácio] E acho que nós estamos pecando aqui por assumir que esse código já é conhecido, então até por falta de tempo (...)... mas eu sinto no início que os alunos se assustam muito por não estarem preparados, ainda mais que é uma disciplina de primeiro semestre. Então eu vejo vários alunos que chegam com aquela mentalidade de colégio... Aproveitem que a química geral tem bons livros em português, porque daqui a pouco vocês não vão conseguir mais estudar por um bom livro em português...".

Essa mesma relação é indicada por outra professora, que salienta a importância da autonomia e da leitura do aluno para a aquisição da compreensão textual, conforme: "[Profa. Dilma]: (...) o jargão ele vai aprender na faculdade. (...) O que ele precisa mais é saber entender um pouco a simbologia, por exemplo. Ele já ter uma noção que existem fórmulas, que existem símbolos (...).Mas eu acho que aluno, (...) ele tem que ter facilidade em interpretar texto, ele tem que ser um tipo de aluno que lê um texto e ele concebe o texto, ele entende o texto. Então ele precisa de uma certa atenção, ele não pode ser um aluno desatento, por exemplo. Tu podes ler um roman- 
ce, tu podes ler um livro e mesmo que tu tenhas uma distração, uma certa desatenção tu consegues pegar a história e parar toda hora. Já num livro de química, não! Tu tens que ler com uma determinada atenção e isso, muitas vezes, é alguma coisa que os alunos, principalmente na idade que entram na faculdade, têm que desenvolver. (...) Só pela lógica ele pode entender matemática e física. Na química, além da lógica, ele precisa de um pouco de vocabulário, mas se ele entra no curso de química e começa a ler livros, ele entra no vocabulário. Então, quando se forma, nem se fala".

A integração das concepções em química com conhecimentos de outras áreas do saber já fora apontada nas representações dos professores. Durante as entrevistas, surgiram manifestações que apontaram as relações que seriam prévias: "[Profa. Dilma] (...) algum conhecimento de matemática, principalmente proporcionalidade, sistemas de equações, regra de três, alguma coisa de logaritmos. Também é necessário que o aluno tenha alguma noção de conceitos de física, principalmente no que se refere à energia, energia potencial, energia cinética. Por que isto? O aluno, ele tem que ter uma certa abstração, já, destes conceitos para chegar na química geral no grau de rapidez com que a gente desenvolve". Ou que aparecem de forma concomitante no currículo: [Prof. Renata]: As disciplinas de química geral acabam sendo ministradas no primeiro semestre junto com cálculo e física. Então de repente tu vais avançando e chega lá em Cinética, e vai definir velocidade instantânea, eles têm que ter noções de limite...".

Nesse sentido, há uma tendência dos professores considerarem os conhecimentos relativos à área de matemática mais relevantes do que os de física: "[Profa. Renata]: (...) eu acho que a gente precisa mais de conceitos de matemática até do que a física, eu acho até, pelo menos na disciplina que eu trabalho (...) eu acho que a matemática é mais importante, porque ela te dá mais base. São conceitos que se tu passas e se tu não sabes, tu não consegues entender". Provavelmente, porque a abordagem é muito mais algorítmica do que fenomenológica.

Nas representações desenvolvidas pelos professores para o conhecimento em química, relativo à área de química geral, bem como nas entrevistas realizadas pelos autores deste artigo com os professores foi possível verificar a influência de suas vivências em suas escolhas da seleção e organização conceitual. Isso foi explicitado, por exemplo, pela professora que produziu a representação mais rica. Quando a Profa. Renata foi questionada sob quais condições realizou a seleção dos conceitos de química, manifestou-se assim: “(...) baseada na minha experiência como professora na disciplina que eu trabalho. E alguma coisa que eu não mais trabalho, mas que eu já trabalhei. (...) antes da reformulação do currículo eu já trabalhei com ligação, modelos atômicos, estados físicos da matéria, além do gasoso. Então isso eu já trabalhei muito tempo, hoje na disciplina que eu trabalho, eu não trabalho mais com ligação química, ficou para depois, não trabalho com modelos atômicos, ficou para depois, não trabalho mais com líquidos e sólidos, o resto mais ou menos se mantém".

A relação entre a formação do professor, suas vivências e o currículo é encontrada em diversas reflexões na área de educação ${ }^{44-46}$. Através dessas reflexões, é possível salientar que o professor é antes de tudo alguém que sabe alguma coisa e cuja função é transmitir esse saber. Entretanto, o próprio saber do professor é um saber plural. Explicitando, é possível supor, ou desejar, a existência de um professor padrão. Ele seria alguém que conheceria sua matéria, sua disciplina e seu programa. Ele deveria possuir certos conhecimentos das ciências da educação e da pedagogia. No entanto, ele não deixaria de desenvolver um saber prático, fundado em sua experiência cotidiana com os alunos.

Os saberes dos professores se encontram vindos de múltiplas perspectivas. Existem os saberes da formação, que são aqueles profissionais, disciplinares e curriculares. Eles foram construídos durante os cursos de graduação. Eles são exteriores aos professores, ou seja, são constituídos em instâncias às quais os professores não têm acesso como produtores.

Em um sistema de ensino que privilegia esses saberes, os professores, muitas vezes, sentem-se desautorizados a selecionar os conteúdos a serem trabalhados com seus alunos. Esse sistema tende a perpetuar alguns conhecimentos previamente selecionados na cultura de referência, conforme é possível depreender da fala de um dos professores: "[Prof. Inácio] (...) os conteúdos da 004, eu peguei do plano da 004 (...) ela funciona mais ou menos padrão, então é uma disciplina que está montada já há bastante tempo. O conteúdo está pronto, o professor que entra na 004 recebe um calhamaço enorme das aulas. Claro que tem liberdade de mexer em algumas coisas, mas o conteúdo está ali."

As reflexões em educação mostram que na sala de aula, onde o currículo de fato se faz, o professor se utiliza de sua cota de liberdade, enfatizando mais alguns tópicos, em detrimento de outros. Essa prática está essencialmente vinculada aos saberes da experiência, que são os saberes adquiridos na prática diária do professor. É possível notar, segundo a percepção dos professores, que os saberes da experiência não têm relação com os saberes de formação, ou mesmo com referenciais teóricos. Isso aparece na fala de um dos professores: "[Prof. Inácio] (...) espero não ter decepcionado vocês (os entrevistadores, que são pesquisadores de educação química) com a minha zero formação em Teoria de Educação. Mas eu acho que muito do que faço, que a grande maioria dos colegas fazem, é intuitivo. A gente sabe que a gente não pode despejar um monte de matéria, a gente sabe que temos que fazer exercícios, a gente tem que tentar tornar a aula agradável, tentar ter um bom relacionamento com os alunos...".

Nesse encontro de saberes, os saberes da prática possibilitam aos professores refletirem sobre os seus cursos de formação. Algumas vezes, a avaliação é feita de forma crítica, como pode ser evidenciado a seguir: "[Prof. Pedro]: (...) eu esqueci de botar (na representação) as reações de transferência de elétrons, que é um grande grupo de reações (...). Aqui no Instituto de Química não é explorado. Eu apontaria como uma deficiência na nossa formação, da minha formação. Quando eu fiz o curso de graduação, foi eu não ter estudado mais um pouco de reações por transferência de elétrons, eu vi rapidamente. Eu agora dou aula de química inorgânica (também), eu procuro trabalhar um pouco isso aqui (...). As reações por transferência de elétrons, explicam muitos processos". Nesse contexto, a descoberta dos limites dos saberes de formação é para o professor uma rejeição do seu conhecimento anterior e a certeza de que o sucesso só depende dele, professor. No ensino superior, em universidades públicas, isso não seria de se estranhar, pois a pesquisa e a atualização são partes fortes do magistério superior.

O mesmo professor aponta uma outra falha em sua formação e tenta justificar o motivo dessa falha: "[Prof. Pedro]: (...) para mim mesmo foi difícil de ver a grande beleza do negócio, eletroquímica e colóides. Para mim, antigamente, era uma coisa que eu não queria nem olhar. 'Ah, não gosto!' Não é que eu não gostasse, é que eu não sabia o suficiente. Tinha medo de enfrentar. Mas isso aqui é super importante, tem coisas que a gente vai renegando, deixando de lado (...)". Então, uma vez que os próprios professores reconhecem a sua falta de maturidade quando eram alunos, não é a toa que entendem que seus atuais alunos não possuem a maturidade que eles gostariam.

$\mathrm{O}$ que foi manifestado por esse professor diz respeito mais à seleção dos conceitos a serem ensinados, do que à seleção de estratégias de ensino. É necessário entender que o tornar-se professor é um processo historicamente elaborado, em geral, dentro de uma perspectiva 
da transmissão do conhecimento acumulado pela humanidade, naturalizado e imprescindível às novas gerações. Nesse sentido, muitos professores têm dificuldades tanto para perceber a pluralidade de seus saberes quanto para identificar a sua produção fora dos contextos oficialmente instituídos, como o manual texto, o ensino formal e a prática laboratorial. Tais dificuldades surgem associadas à aceitação da norma vigente, conforme se depreende da crítica que uma das professoras faz à formação do ensino médio de seus alunos: "[Profa. Renata] (...) de repente eu estou viciada na maneira como eu aprendi! Quando a gente estudava, sei lá o que acontecia. Talvez eu esteja cristalizada nessa maneira que eu aprendi as coisas, mas o fato é que eu entrei na faculdade sabendo mais coisas do que eles sabem agora...".

Entretanto, não se pode pensar que essa cristalização não teria solução. Em determinado momento, algum dos saberes da experiência ou das vivências do professor, dentro ou fora da sala de aula, podem servir de água régia e dissolver o que parecia tão cristalizado. É possível exemplificar a mudança de conduta: "[Profa. Dilma]: (...) na realidade, não foi a concepção dos alunos, quem mudou fui eu! (...). Mas por que eu mudei? Porque eu precisei ter filhos, entrar nesta idade e explicar a matéria e ver que na realidade o problema não é do aluno, quer dizer, o problema não é do erro do conceito, mas é da maturidade do aluno. $O$ aluno não tem maturidade para conceitos abstratos. Então hoje eu penso o seguinte. Antes eu pensava assim: não é para dar errado, tem que dar desde o primeiro momento o conceito absolutamente certo. Se o aluno não tem condições de aprender, ele em algum momento vai aprender. Hoje eu acho diferente, eu acho que se é para dar errado, é preciso que não se dê. (...) Quando o aluno tem um conceito errado, vem com um conceito errado do $2^{\circ}$ grau e eu vou ensinar o conceito que realmente é, a forma que eu vou considerar é muito mais complexa do que a forma que ele aprendeu. Ele não troca, ele não troca o conteúdo mais certo por aquele conteúdo errado. Ele fixa demais o conteúdo mais simples, o conteúdo mais fácil". Essa percepção da professora tem sido apontada por investigações em educação em ciências sobre as demandas cognitivas e sobre a mudança conceitual ${ }^{47}$.

Finalmente, é possível identificar que essa mudança na percepção sobre a aprendizagem do aluno e sobre o ensino do professor está relacionada com a percepção sobre o encadeamento dos conceitos e, em conseqüência, sobre o currículo: "[Profa. Dilma]: (...) eи acho que agora tem mais lógica (o currículo, veja a Tabela 3). Eu fui uma pessoa resistente à mudança. Eu achava que a gente tinha que começar aquele conhecimento crescente do conceito. Então tu começas assim: tu pegas o átomo, aí tu estudas lá dentro próton, nêutron, elétron. Daí tu começas a construir o modelo e do modelo tu constróis a molécula. Aí da molécula, enfim, tu vais agregando a matéria. Uma agregação de matéria é uma forma de construir conhecimento e eu estava convencida que aquele era o melhor método. Mas hoje eu penso diferente, eu acho que a forma como é feito agora está melhor, porque tu primeiro vês a transformação da matéria e tu tentas explicar a transformação da matéria em termos de energia e de tempo. 'Por que ela acontece?' E só depois, então, que o aluno tem essa noção de transformação em termos de equilíbrio, em termos de termodinâmica, em termos de energia, aí então que ele vai entrar naquele microcosmo, como se fosse estudar uma termodinâmica a nível atômico".

\section{CONCLUSÕES}

A participação do professor é essencial para que uma reflexão crítica de seu curso de formação inicial possa desencadear, também, uma reflexão sobre sua prática docente. Portanto, essa investigação procurou evidenciar as percepções dos professores, sobre a seleção e a integração do conhecimento em química, a partir de seu processo pedagógico em sua realidade de ensino. Nesse sentido, podem ser ressaltadas duas amplas conclusões, uma que guarda relação com as representações conceituais, outra com as entrevistas realizadas com os professores.

Em relação à primeira dessas conclusões, assim como indicava a literatura, as falas dos professores permitiram evidenciar as dificuldades na sistematização da integração conceitual e, acima de tudo, o forte caráter subjetivo que norteou a construção das representações. Apesar disso, foi possível inferir semelhanças na enumeração dos conceitos. As informações obtidas na análise das representações dos professores nos permitiram desenvolver uma estratégia de investigação da enunciação em livros textos de química geral para o ensino superior $^{26,27}$.

Em relação à segunda conclusão, a entrevista com os professores tornou-se essencial, visto que reforçou questões de cunho pessoal, nas quais a experiência nas disciplinas ministradas é considerada determinante da postura pedagógica, influenciando diretamente na construção e na comunicação dos conceitos trabalhados pelos professores. Portanto, esses fatores vivenciais e, por isso, arbitrários, influem sobre a seleção, a organização e a forma de abordagem realizadas pelos professores. Sob essas escolhas dos professores é que se dão os primeiros contatos do estudante com a ciência química.

Nesse sentido, algumas extrapolações podem ser possíveis. A realidade a seguir já foi apontada na introdução, mas aqui serve de reiteração. Uma ampla pesquisa sobre o processo de ensino e de aprendizagem em química geral ${ }^{48}$, realizada em 42 instituições de ensino superior nos Estados Unidos da América, revelou que os estudantes têm dificuldade de entender e aplicar os conceitos, achar relevância, transferir conhecimento entre as disciplinas e identificar e desenvolver as habilidades necessárias para o sucesso acadêmico ou na carreira. Essa situação teria relação com a diversidade da preparação acadêmica dos estudantes, sua inserção cultural e motivação, bem como os objetivos para sua carreira.

Entretanto, por essa pesquisa se foi além do diagnóstico, apontando-se algumas recomendações para aperfeiçoar o processo de ensino e de aprendizagem de química geral. Entre essas, indica-se:

a) A crítica é que a integração dos conceitos e do conteúdo do curso é deixada para os estudantes, que, na maioria das vezes, manifestam dificuldades com essa integração. Portanto, sugere-se ampliar a integração entre as disciplinas iniciais dos cursos de química, física e matemática. Essa integração possibilitaria uma completa discussão dos conceitos químicos, abrindo o caminho para a comparação e os contrastes entre as disciplinas, elevando o processo de transposição do conhecimento para novos contextos, em um empreendimento intelectual equivalente à aprendizagem de novos conteúdos. Por exemplo, a cultura da física considera uma explicação em termos de força, enquanto a cultura da química provê explicações em termos de propriedades da matéria. Em um curso integrado, essas diferentes perspectivas seriam reconciliadas e se procuraria uma explicação com um entendimento mais profundo.

b) A crítica é que as faculdades de química, geralmente, têm encontrado barreiras para usar a escrita em seus cursos, apesar dos profissionais dessa área mostrarem notáveis deficiências com essa habilidade. Em contraposição, sugere-se que exercícios de escrita devem ser usados para promover entendimento conceitual, integração com outras disciplinas, relevância e enriquecimento do arcabouço referencial. Tais exercícios escritos poderiam ser apresentados e solicitados em diversos formatos: resumo, notas bibliográficas, artigos para revistas, pequenos ensaios escritos em classe, artigos conceituais, revisão da literatura, artigos de popularização, artigos históricos ou filosóficos.

c) A crítica mostra a persistência de concepções alternativas ao conhecimento em química mesmo nos alunos que obtiveram sucesso na disciplina de química geral. Assim, recomenda-se que é necessário um maior esforço por parte do professor em identificar tais 
concepções alternativas e ser hábil para elaborar questões chaves que levem o estudante a se confrontar com as falhas de suas concepções em explicar o fenômeno natural.

O cerne dessas críticas é que o professor que opta pelo formato de aula tradicional não considera relevantes as teorias educacionais que demonstram as vantagens de envolver ativamente o aluno em seu processo de aprendizagem.

Um outro artigo ${ }^{49}$, sugere mais algumas estratégias:

d) A ampliação do tempo para discussões conceituais em sala de aula. A eficiência dessa alternativa pode ser verificada durante a avaliação dos estudantes. Eles teriam se engajado mais nessas abordagens não-tradicionais. Eles apontaram que essa estratégia permitiu que eles identificassem suas deficiências de conhecimento e relacionassem conceitos, organizando-os de modo significativo.

e) A utilização de mapas conceituais. Durante a avaliação de suas atividades, os estudantes perceberam que essa estratégia possibilitou o acesso a novas informações, a fixação das necessidades para um próximo tópico curricular a ser estudado ou para o exame e a organização dos conceitos de um modo mais significativo.

Sem dúvida, essas estratégias são muito interessantes. No entanto, a questão chave se dá sobre a maneira de promovê-las. É importante que os professores reflitam sobre sua formação e sobre sua prática docente, como atestam as falas dos professores neste artigo. Mas é preciso, também, que se avance da reflexão para a ação ${ }^{50}$, por exemplo, com a incorporação das estratégias citadas nos cursos de química geral.

Neste trabalho buscamos conhecer um pouco mais o enredamento conceitual a partir da visão dos professores. Uma vez que não foi possível depreender das seleções feitas pelos professores uma estrutura comum, a continuidade de nosso trabalho se dará sobre estruturas comuns parciais para os conceitos mais representativos na opinião dos professores. Dessa forma, o enredamento proposto para conceitos como equilíbrio químico, ligação química e termodinâmica será utilizado na comparação com a estrutura presente nos principais livros didáticos de química geral utilizados por estudantes de graduação em química.

Finalmente, esse caminho de reflexão sobre a organização conceitual, sob o ponto de vista dos professores e sobre a estrutura dos livros didáticos visa buscar alternativas pedagógicas mais razoáveis para os iniciantes dos cursos de química. O diagnóstico da origem dos problemas enfrentados pelos estudantes, no início de seus cursos de química, está evidenciado nas falas dos professores e das professoras. Alternativas para minimizar tais obstáculos à aprendizagem em química estão disponíveis na literatura sobre educação química. O que falta, então? O caminho, sem dúvida, é de muito diálogo. Esperamos, com este trabalho, contribuir para a continuidade do diálogo.

\section{AGRADECIMENTOS}

Gostaríamos de agradecer aos professores que participaram desta nossa investigação e à FAPERGS, pela bolsa de iniciação científica concedida, que permitiu desenvolver este trabalho.

\section{REFERÊNCIAS}

1. Machado, A. H.; Aula de química: discurso e conhecimento, Unijuí: Ijuí, 2000.

2. Mortimer, E. F.; Linguagem e formação de conceitos no ensino de ciências, UFMG: Belo Horizonte, 2000.

3. Araújo, D. X.; Silva, R. R.; Tunes, E.; Quim. Nova 1995, 18, 80.

4. Gomes, L. A. K.; Quim. Nova na Escola 1998, 8, 15.

5. Maldaner, O. A.; Piedade, M. C. T.; Quim. Nova na Escola 1995, 1, 15.

6. Oliveira, R. J.; Santos, J. M.; Quim. Nova na Escola 1998, 8, 19.

7. Machado, A. H.; Moura, A. L. A.; Quim. Nova na Escola 1995, 2, 27.

8. Nunez, I. B.; Pacheco, O. G.; Quim. Nova 1996, 19, 675.

9. Echeverria. A. R.; Quim. Nova na Escola 1996, 3, 15.

10. Mortimer, E. F.; Miranda, L. C.; Quim. Nova na Escola 1995, 2, 23.

11. Campos, R. C.; Silva, R. C.; Quim. Nova na Escola 1999, 9, 18.

12. Justi, R. S.; Quim. Nova na Escola 1998, 7, 26.

13. Lopes, A. R. C.; Quim. Nova na Escola 1995, $2,7$.

14. Mortimer, E. F.; Em Aberto 1998, 7, 25.

15. Schnetzler, R. P.; Quim. Nova 1981, 4, 6.

16. Justi, R. S.; Ruas, R. M.; Quim. Nova na Escola 1997, 5, 24.

17. Lopes, A. R. C.; Quim. Nova na Escola 1996, 4, 21.

18. Machado, A. H.; Aragão, R. M. R.; Quim. Nova na Escola 1996, 4, 18.

19. Mortimer, E. F.; Amaral, L. O. F.; Quim. Nova na Escola 1998, 7, 30

20. Lopes, A. R. C.; Episteme 1998, 3, 119.

21. Romanelli, L. I.; Quim. Nova na Escola 1996, 3, 27.

22. Del Pino, J. C.; Lopes, C. V. M.; Espaço da Escola 1997, 25, 43.

23. Lopes, C. V. M.; Krüger, V.; Del Pino, J. C.; Ed. Quimica 2000, 11, 214.

24. Lopes, C. V. M.; Dissertação de Mestrado, Universidade Federal do Rio Grande do Sul, Brasil, 2001.

25. Krüger, V.; Tese de Doutorado, Pontifícia Universidade Católica do Rio Grande do Sul, Brasil, 2000.

26. Finatto, M. J. B.; Enzweiler, N.; Huang, C.; Eichler, M. L.; Del Pino, J. C.; TradTerm 2002, 8, 211.

27. Finatto, M. J. B.; Eichler, M. L.; Del Pino, J. C.; Organon, no prelo.

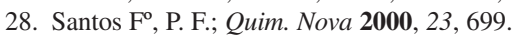

29. Duchovic, R. J.; J. Chem. Educ. 1998, 75, 856

30. Silva, R. R.; Tunes, E.; Pachá, L. C. L.; Junqueira, R. M. P.; Quim. Nova 1995, 18,210

31. Cunha, A. M.; Tunes, E.; Silva, R. R.; Quim. Nova 2001, 24, 262.

32. Bello, L.; Ed. Quim. 2000, 11, 374.

33. Pliego, O. H.; Odetti, H.; Ortolani, A.; Ed. Quim. 2001, 13, 20.

34. Schummer, J.; Ed. Quim. 1999, 10, 92

35. Atkins, P.; Pure Appl. Chem. 1999, 71, 927.

36. Gillespie, R. J.; J. Chem. Educ. 1997, 74, 862.

37. Pauling, L.; J. Chem. Educ. 1980, 57, 38.

38. Lévy, P.; As tecnologias da inteligência, São Paulo, 1993, p. 34.

39. Martin, J.; Hiperdocumentos e como criá-los, Campus: Rio de Janeiro, 1992.

40. Silva, S. M.; Eichler, M. L; Del Pino, J. C.; Livro de Resumos do XI Salão de Iniciação Científica da Universidade Federal do Rio Grande do Sul, Porto Alegre, Brasil, 1999.

41. Rosa, M. I. F. P.S.; Schnetzler, R. P.; Quim. Nova na Escola 1998, 8, 31.

42. Driver, R.; Asoko, H.; Leach, J.; Mortimer, E.; Scott, P.; Quim. Nova na Escola 1998, 9, 31 .

43. Krieger, M. G.; Maciel, A. M. B., orgs.; Temas de terminologia, UFRGS: Porto Alegre, 2002.

44. Moreira, A. F. B.; Silva, T. T., orgs.; Currículo, cultura e sociedade, Cortez: São Paulo, 1994.

45. Tardif, M.; Lessard, C.; Lahaye, L; Teoria \& Edu. 1991, 4, 215.

46. Moreira, A. F. B.; Quim. Nova na Escola 1999, 9, 23.

47. Pozo, J. I.; Crespo, M. A. G.; Aprender y enseñar ciencia, Morata: Madrid, 1998.

48. Hanson, D.; Wolfskill, T.; J. Chem. Educ. 1998, 75, 143.

49. Francisco, J. S.; Nicoll, G.; Trautmann, M.; J. Chem. Educ. 1998, 75, 210.

50. Schön, D. A.; Educando o profissional reflexivo: um novo design para o ensino e a aprendizagem, Artes Médicas: Porto Alegre, 2000. 